AKADEMIE DER LANDWIRTSCHAFTSWISSENSCHAFTEN DER DEUTSCHEN DEMOKRATISCHEN REPUBLIK

ARCHIV

FÜR

NATURSCHUTZ

UND

LANDSCHAFTS-

FORSCHUNG

吕

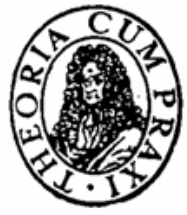

HEFT $4 \cdot 1982 \cdot$ BAND 22

\title{
ISSN 0003-9306
}

Arch. Naturschutz u. Landschaftsforsch. · Berlin 22 (1982) 4, 205-252

EVP 5,- M 